\title{
Comparison of Plethysmographic and Helium Dilution Lung Volumes
}

\section{Which Is Best for COPD?}

\author{
Carl R. O’Donnell, ScD, MPH; Alexander A. Bankier, MD; Leopold Stiebellehner, MD; \\ John J. Reilly, MD, FCCP; Robert Brown, MD; and Stephen H. Loring, MD
}

\begin{abstract}
Background: Theoretical considerations and limited scientific evidence suggest that whole-body plethysmography overestimates lung volume in patients with severe airflow obstruction. We sought to compare plethysmography (Pleth)-, helium dilution (He)- and CT scan-derived lung volume measurements in a sample containing many patients with severe airflow obstruction.

Methods: We measured total lung capacity (TLC) in 132 patients at three hospitals, with monitored application of recommended techniques for Pleth and He measurements of lung volume and by thoracic CT scans obtained during breath hold at full inspiration.

Results: Average TLC among 132 subjects was $6.18 \mathrm{~L}$ ( $\pm 1.69 \mathrm{~L}$ ) by Pleth-derived TLC, $5.55 \mathrm{~L}( \pm 1.39 \mathrm{~L})$ by He-derived TLC, and $5.31 \mathrm{~L}( \pm 1.47)$ by CT scan-derived TLC. Pleth-derived TLC was significantly greater than either He-derived TLC or CT scan-derived TLC $(P \leq .001)$, whereas there was no significant difference between He-derived and CT scan-derived values. When examined separately, there were significant within-subject differences in TLC by measurement technique among subjects with airflow obstruction, but not among those without airflow obstruction. Plethysmographic overestimation of TLC was greatest among subjects with $\mathrm{FEV}_{1}<30 \%$ of predicted.

Conclusions: In the setting of airflow obstruction, Pleth systematically overestimates lung volume relative to He or thoracic imaging despite adherence to current recommendations for proper measurement technique.

CHEST 2010; 137(5):1108-1115
\end{abstract}

Abbreviations: $\mathrm{He}=$ helium dilution; $\mathrm{LVRS}=$ lung volume reduction surgery; PFT = pulmonary function test; Pleth = plethysmography; TGV = thoracic gas volume; TLC $=$ total lung capacity

$\mathbf{T}_{\mathrm{i}}$ otal lung capacity (TLC) is commonly measured in the pulmonary function testing (PFT) laboratory either by gas dilution (usually with helium [He]), or whole-body plethysmography (Pleth). These two techniques yield equivalent results among those with normal lung mechanical function. ${ }^{1}$ However, conven-

Manuscript received June 25, 2009; revision accepted November $13,2009$.

Affiliations: From the Departments of Anesthesia and Critical Care (Drs O'Donnell and Loring) and Radiology (Dr Bankier), Beth Israel Deaconess Medical Center; Pulmonary and Critical Care Medicine (Dr Reilly), Brigham and Women's Hospital; Pulmonary and Critical Care Medicine Unit and Medicine (Dr Brown), Massachusetts General Hospital; Harvard Medical School (Drs O'Donnell, Loring, Bankier, Reilly, and Brown), Boston, MA; and the Department of Pulmonology (Dr Stiebellehner), Medical University of Vienna, Vienna, Austria.

Funding/Support: This work was supported in part by the National Heart, Lung, and Blood Institute [Grant HL-52586]. Correspondence to: Carl R. O'Donnell, ScD, MPH, Beth Israel Deaconess Medical Center, Dana 717, 330 Brookline Ave, Boston, MA 02215; e-mail: codonne1@bidmc.harvard.edu tional wisdom suggests that in the setting of heterogeneous airflow obstruction, such as occurs in COPD or asthma, Pleth is more accurate. Indeed, an early version of the Official Statement of the European Respiratory Society on Lung Volumes and Forced Ventilatory Flows recommended, "The plethysmographic determination of thoracic gas volume is the method of choice in patients with airflow limitation and air trapping,"2 although the most recent revision of these guidelines does not make this recommendation. ${ }^{3}$ This wisdom is rooted in the logic that rebreathed helium fails to equilibrate fully with gas contained in poorly ventilated (slow) lung regions, and that the volume of gas contained within these

() 2010 American College of Chest Physicians. Reproduction of this article is prohibited without written permission from the American College of Chest Physicians (www.chestpubs.org/ site/misc/reprints.xhtml).

DOI: $10.1378 /$ chest.09-1504 
slow regions is, therefore, not incorporated in the helium estimate of TLC. Alternatively, it is assumed that volume is accurately measured by Pleth if the gas within all regions of the lung and the airways undergoes equal and synchronous compression/decompression during panting maneuvers. Despite this assumption, there are theoretical considerations, supported by limited research, ${ }^{4-10}$ suggesting that Pleth-derived TLC may overestimate lung volume, particularly in very severe airflow obstruction.

Current recommendations for plethysmographic technique are supported by evidence that lung volume measurement in COPD is accurate when panting frequency is $<1 \mathrm{~Hz}$ and cheeks are supported to minimize compliance of, and gas flow to and from, the upper airway. ${ }^{9,10}$ To date, these recommendations have not been validated in subjects with very severe obstruction. Rodenstein and Stănescu ${ }^{9}$ first demonstrated that frequency dependence of plethysmographic volume observed among patients with asthma during bronchoconstriction was minimized at a panting rate of $1 \mathrm{~Hz}$. However, their sample did not contain any subjects with $\mathrm{FEV}_{1}<1 \mathrm{~L}$. Andersson et al ${ }^{11}$ found acceptable agreement between Pleth-derived TLC and He-derived TLC "except in patients with very severe lung disease," but that study included very few subjects with severely reduced $\mathrm{FEV}_{1}$. Similarly, Shore et al ${ }^{10}$ examined the relationship between panting frequency and plethysmographic accuracy in patients with COPD, but studied only two subjects with $\mathrm{FEV}_{1}<1 \mathrm{~L}$, and none with $\mathrm{FEV}_{1}<0.75 \mathrm{~L}$. By contrast, patients with very severe COPD, such as candidates for lung volume reduction surgery (LVRS), often have $\mathrm{FEV}_{1}<0.75 \mathrm{~L}^{12}{ }^{12} \mathrm{We}$ are not aware of any experimental evidence for the relative accuracy of plethysmographic vs gas dilution TLC when recommended techniques are applied to a sample containing patients with severe airflow obstruction. We questioned whether Pleth may lead to systematic overestimation of lung volume in very severe obstruction. To address this question, at three hospitals from January 1999 through October 2005, we compared TLC measured using recommended techniques by Pleth, He, and CT scans of the thorax in 132 subjects, many of whom had severe COPD.

\section{Materials AND Methods}

All subjects were selected from among patients scheduled for a clinically indicated chest CT scan, and all provided written informed consent according to a protocol approved by the local institutional review board. At each hospital, subjects underwent spiral CT scanning of the entire lung field at full inspiration in the supine position. Breath-hold time varied from approximately 15 to $25 \mathrm{~s}$ depending on lung height. Subjects at two hospitals (H1 and H2) were recruited from patients undergoing thoracic CT scanning for a variety of clinical indications. Subjects at the third hospital (H3) were undergoing clinical evaluation for LVRS During CT scanning, subjects received standard instructions to take in a "deep breath" and hold it throughout the scan. At H1, lung volumes were monitored spirometrically during the CT scan maneuvers. Following image acquisition, subjects remained on the mouthpiece and performed a slow vital capacity maneuver to measure any difference between the deep breath and TLC. Each CT scanning TLC at H1 was individually corrected for the observed difference between breath-hold and full inspiratory volume. At H2, subjects were read instructions from a prepared script, and performed practice maneuvers to assure correct test performance. (These procedures are summarized in a separate publication ${ }^{13}$ ). At $\mathrm{H} 3$, subjects were enrolled in a treatment trial that required serial thoracic CT scan evaluation, and they were thus well practiced in the procedure. The scans were transferred to a workstation and analyzed using custom software to estimate lung gas volume on CT scan slices every $1 \mathrm{~cm}$ from apex to base of each lung. The area of lung on each slice was determined using a masking program, manually excluding any dense structures within the lung. Using tracheal gas and ventricular blood as benchmarks, gas volume was computed within each slice based on a standardized density scale. ${ }^{14}$ All CT scan analyses were performed in a single laboratory using the same procedure. As a check of reproducibility, an independent operator repeated analysis on 10 sets of CT images selected to represent a wide range of TLC.

All patients underwent PFT within 2 months of the CT scan. No subjects underwent surgery between CT scan and PFT. During Pleth-derived and He-derived TLC measurements, subjects were tested in the upright seated position and breath-by-breath data were collected for assessment of data quality and adherence to recommended procedures. ${ }^{10,15}$ For He-derived TLC, the end-of-test criterion (equilibration) was defined as helium concentration change of $0.02 \%$ or less during $30 \mathrm{~s}$ of rebreathing. For Plethderived TLC, cheeks were supported and panting frequency was $<1 \mathrm{~Hz}$, creating linear traces of mouth pressure vs box pressure. A minimum of three acceptable tracings were averaged for plethysmographic volume determinations, and one acceptable maneuver was performed to obtain He-derived volume estimates. The performance standards for pulmonary tests at all sites were those recommended by American Thoracic Society/European Respiratory Society guidelines. No additional training was provided. PFTs were conducted on Collins equipment at H1 (Ferraris Respiratory; Louisville, CO), Collins and Jaeger equipment (Yorba Linda, CA) at H2, and P.K. Morgan equipment (Haverhill, MA) at H3.

Comparisons among techniques were made using the graphic method described by Bland and Altman. ${ }^{16}$ Statistical differences were assessed by analysis of variance with technique, site, and the presence of airflow obstruction as fixed factors. The Scheffe method was used for pairwise post hoc comparison of within-subject differences in TLC by measurement technique. Probability $<.05$ (two-tailed) was considered significant.

\section{RESULTS}

We studied 40 patients at $\mathrm{H} 1,51$ at $\mathrm{H} 2$, and 41 at H3 for a total of 132. Subject characteristics are provided in Table 1 . There was no significant difference by hospital with respect to age or sex distribution. Reflecting the selection of subjects at $\mathrm{H} 3$ from candidates for volume reduction surgery, average $\mathrm{FEV}_{1}$ was substantially lower. All subjects at $\mathrm{H} 3 \mathrm{had} \mathrm{FEV}_{1} / \mathrm{FVC}$ ratio $<0.65$, compared with $45 \%$ and $40 \%$ of subjects at $\mathrm{H} 1$ and $\mathrm{H} 2$, respectively. Independent repeat analysis of 10 CT scans from subjects at two hospitals among 
Table 1-Subject Characteristics by Site

\begin{tabular}{|c|c|c|c|c|c|}
\hline Hospital & No. & $\mathrm{FVC}(\mathrm{L})$ & $\mathrm{FEV}_{1}(\mathrm{~L})$ & Age & No. (\%) Obstructed \\
\hline $\mathrm{H} 1$ & 40 & $2.92(0.99)$ & $1.87(1.10)$ & $58.7(12.6)$ & $18(45)$ \\
\hline $\mathrm{H} 2$ & 51 & $3.28(0.99)$ & $2.21(0.82)$ & $60.9(11.2)$ & $20(39.2)$ \\
\hline H3 & 41 & $2.44(0.76)$ & $0.75(0.31)$ & $60.2(9.8)$ & $41(100)$ \\
\hline Total & 132 & $2.90(0.98)$ & $1.63(1.00)$ & $60.0(11.2)$ & $79(59.8)$ \\
\hline
\end{tabular}

whom TLC ranged from $2.06 \mathrm{~L}$ to $7.27 \mathrm{~L}$ revealed an average difference of $0.12 \mathrm{~L}\left(R^{2}=0.99\right)$.

Figure 1 shows Bland-Altman plots of Pleth - CT scan, HE - CT scan, and Pleth - He differences in TLC by CT scan TLC. Although He - CT scan TLC values cluster symmetrically about the line of identity, Pleth - CT and Pleth - He values cluster above it. Mean TLC was $6.18 \mathrm{~L}( \pm 1.69 \mathrm{~L}, \mathrm{SD})$ by Pleth, $5.55 \mathrm{~L}( \pm 1.39 \mathrm{~L})$ by He, and $5.31 \mathrm{~L}( \pm 1.47 \mathrm{~L})$ by CT scan (Fig 2). Within-subject TLC varied significantly by technique $(P=.001)$ and the presence of obstruction (defined as $\mathrm{FEV}_{1} / \mathrm{FVC}$ ratio $\left.<0.65\right)(P \leq .001)$, but not by site (Table 2). In post hoc comparisons of TLC by technique, Pleth-derived TLC was significantly greater than either He-derived TLC $(0.63 \mathrm{~L}$, $P=.001)$ or CT scan-derived TLC $(0.87 \mathrm{~L}, P=.001)$. There was no significant difference between He-derived and CT scan-derived TLC. There was a significant interaction of site by obstruction. Because all subjects at H3 were obstructed, we could not examine the influence of obstruction separately within site. We therefore examined the influence of site separately among subjects with airflow obstruction.

Among those with airflow obstruction, mean TLC was $7.03 \mathrm{~L}( \pm 1.43 \mathrm{~L})$ by Pleth, $6.10 \mathrm{~L}( \pm 1.23 \mathrm{~L})$ by $\mathrm{He}$, and $5.95 \mathrm{~L}( \pm 1.20 \mathrm{~L})$ by CT scan (Fig 3$)$. Withinsubject TLC varied significantly by technique $(P=.009)$, but not by site (Table 3$)$. In post hoc comparisons of TLC by technique, plethysmographic TLC was significantly greater than either He-derived TLC $(0.93 \mathrm{~L}, P<.001)$ or CT scan-derived TLC $(1.07 \mathrm{~L}, P<.001)$. There was no significant difference between He-derived and CT scan-derived TLC. Among nonobstructed subjects at $\mathrm{H} 1$ and $\mathrm{H} 2$, there was no significant within-subject variance of TLC by technique.

To assess the dependence of plethysmographic TLC on severity of airflow obstruction, we examined plots of Pleth - CT scan and Pleth - He differences vs percent predicted $\mathrm{FEV}_{1}$ among subjects without volume restriction. There was a distinct break at low $\mathrm{FEV}_{1}$ such that most of the larger differences $(>1 \mathrm{~L})$ occurred among subjects with $\mathrm{FEV}_{1}<30 \%$ of predicted. We therefore performed logistic regression of dichotomizedby-technique differences in TLC $(>1 \mathrm{~L}$ vs $\leq 1 \mathrm{~L})$ on $\mathrm{FEV}_{1}(\geq 30 \%$ vs $<30 \%$ predicted). A $>1$ L by-technique volume difference was significantly more likely among subjects with low $\mathrm{FEV}_{1}$ for both Pleth - CT scan (odds ratio $[\mathrm{OR}]=2.45,95 \% \mathrm{CI}=1.06-5.63)$ and Pleth $-\mathrm{He}$ $(\mathrm{OR}=2.53,95 \% \mathrm{CI}=1.09-5.86)$. There was no significant difference for He - CT scan (Table 4).

\section{DisCUSSION}

We have demonstrated that, in the setting of airflow obstruction, plethysmographic TLC is significantly greater than either CT scan- or He-derived
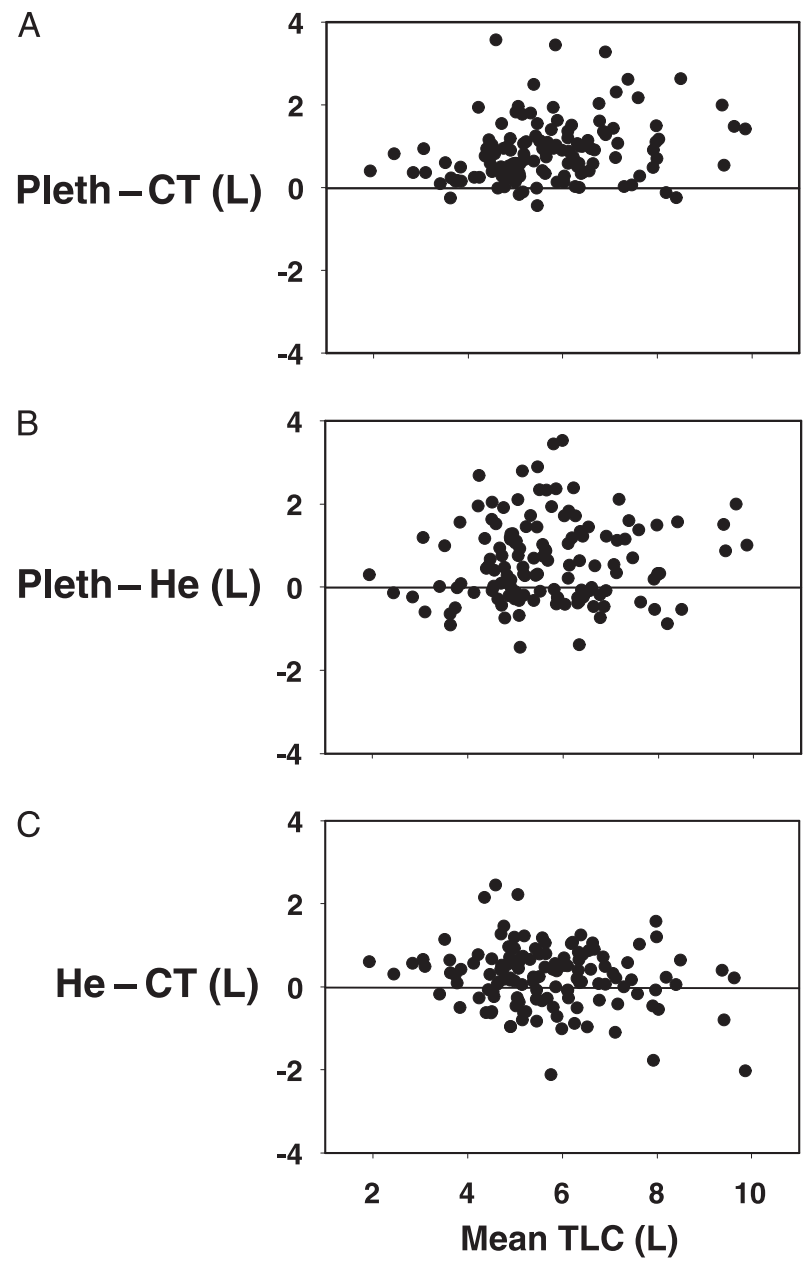

Figure 1. Bland-Altman plots of Pleth-derived TLC-CT scanderived TLC vs mean TLC (A), Pleth-derived TLC - HE-derived TLC vs mean TLC (B), He-derived TLC - CT scan-derived TLC vs mean TLC $(C)$. He=helium dilution; Pleth=plethysmography; $\mathrm{TLC}=$ total lung capacity. 


\section{Average TLC by Measurement Technique: All Subjects}

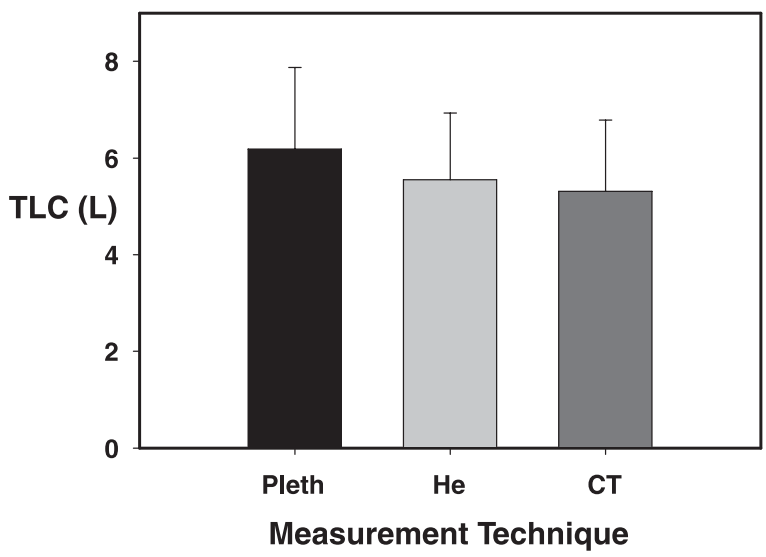

Figure 2. Average TLC by technique among all subjects. $\mathrm{T}$ bars indicate SDs. See Figure 1 legend for expansion of abbreviations.

TLC, whereas CT scan- and He-derived TLC are not significantly different from each other. Very large differences of $>1$ L between Pleth-derived TLC and either CT scan- or He-derived TLC are significantly more likely to occur in severe airflow obstruction when the $\mathrm{FEV}_{1}$ is $<30 \%$ of predicted. These findings suggest that Pleth overestimates lung volume, particularly in the setting of severe airflow obstruction. If the Pleth- and He-derived results were to be considered in the absence of CT scan-derived data, the observed Pleth- and He-derived TLC difference would be consistent with the conventional interpretation that there is significant underestimation of (trapped) gas volume by the He method.

Measurement of absolute lung volume lacks any gold standard for comparison. Each of the several available techniques is based on a solid foundation of physical principles, but all are limited by factors such as subject and operator characteristics and the inherent precision of measurement system components.
Guidelines and recommendations for equipment specifications and test administration ideally achieve measurement accuracy with respect to an external physical standard. Although there are physical models available to check equipment calibration, there are no acceptable biologic models that can be referenced to external physical standards. Realistically, guidelines help assure intrasubject consistency across laboratories and test techniques. The same result should be obtained on a given patient tested in any laboratory using any technique. With this in mind, we used three well-standardized techniques to estimate total lung capacity.

Various techniques for radiographic estimation of lung volume have been described over several decades. Particular interest has been paid to thoracic CT scanning as this imaging modality is less prone to inaccuracies related to chest wall or image distortion. As with the other lung volume measurement techniques, the accuracy of CT scan-derived TLC depends on several assumptions: that breath is held at maximal inhalation; that lung volume at maximal inhalation does not differ significantly between the supine position in which images are acquired and the upright position maintained during He- and CT scan-derived volume measurement; that image analysis does not vary among operators; that the analysis algorithm can discriminate between intrathoracic gas and tissue; and that intrathoracic distances, and, hence, area or volume, can be accurately measured.

There is little question that CT scanners can discriminate linear distances, just as it is well established that transducers in a plethysmograph can accurately resolve very small and rapid changes in pressure, or that analyzers can resolve gas concentrations well within the accuracy required for He measures. Significant interscanner variability of lung density measurement has been reported, but much of this is attributable to variability in lung volume (volume at breath hold relative to TLC), a factor we attempted

Table 2-Analysis of Variance for Within-Subject Variance of Total Lung Capacity by Test Type, Test Site, and the Presence of Airflow Obstruction

\begin{tabular}{|c|c|c|c|}
\hline Outcome & Variance Source & $F$ Ratio & $P$ Value \\
\hline \multirow[t]{7}{*}{ Within-subject TLC } & Test type & 6.65 & .001 \\
\hline & Site & 0.21 & .809 \\
\hline & Obstructed & 22.91 & $<.001$ \\
\hline & $\underline{\text { Interactions }}$ & & \\
\hline & Test type $\times$ site & 2.12 & .077 \\
\hline & Test type $\times$ obstructed & 1.07 & .344 \\
\hline & Site $\times$ obstructed & 8.26 & $<.001$ \\
\hline \multicolumn{4}{|c|}{ Post hoc Comparisons (Scheffe) } \\
\hline Volume Comparison & Mean Difference, L & $P$ Value & $95 \% \mathrm{CI}$ \\
\hline Pleth - He & 0.63 & .001 & $0.21-1.06$ \\
\hline Pleth - CT scan & 0.87 & $<.001$ & $0.44-1.29$ \\
\hline $\mathrm{He}-\mathrm{CT}$ scan & 0.24 & .391 & -0.19 to 0.66 \\
\hline
\end{tabular}

$\mathrm{He}=$ helium dilution; Pleth = plethysmography; TLC = total lung capacity. 


\section{Average TLC by Measurement Technique: Obstructed Subjects}

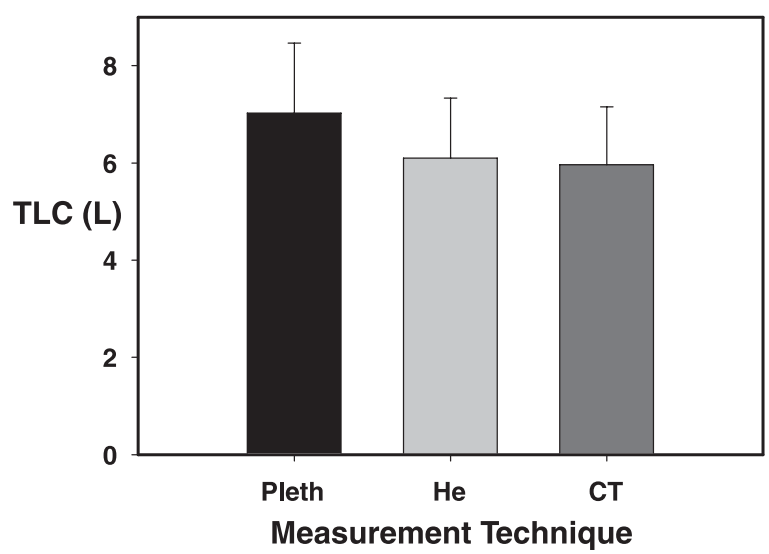

FIGURE 3. Average TLC by technique among obstructed subjects. $\mathrm{T}$ bars indicate SDs. See Figure 1 legend for expansion of abbreviations.

to control across sites. ${ }^{17}$ With regard to operator reliability, independent parallel analyses in a subset of our data demonstrated excellent interrater agreement of CT scan-derived TLC. Thus, we believe the relative accuracy of CT scan- compared with He- or Pleth-derived TLC is largely dependent on subject performance.

To assure that thoracic CT scans were acquired at maximal inspiratory breath hold (TLC), CT scanning operators at each site provided specific instructions. At one study site $(\mathrm{H} 1)$, subjects were monitored by spirometer to assess the breath hold relative to maximal lung volume. Subjects were encouraged to breathe in as much as possible immediately before and again after scanning. At another site (H2), subjects were read instructions from a prepared script, and performed practice maneuvers to assure correct test performance. Subjects at the third site had become accustomed to CT scanning procedures through repeated serial measurements prior to enrollment in our study.

Despite maximal inspiratory effort, TLC may be less in the supine position, largely because of the influence of gravity on the abdominal contents leading to increased inspiratory diaphragmatic load. Several studies have examined the influence of posture on vital capacity with variable results. We recently studied 70 healthy volunteers ranging in age from 25 to 75 years, and found the average upright vs supine reduction in vital capacity was $<3 \%$. ${ }^{18}$ This average upright-to-supine difference is about one-third the magnitude of the volume difference we observed between Pleth- and CT scan-derived TLC. The slightly higher average value of He- than CT scan-derived TLC in our sample may be attributable to postural dependence.

Lung volume determination by helium was first described by Meneely and Kaltreider. ${ }^{19}$ Subjects rebreathe through a spirometer primed with a gas mixture that includes helium and, after equilibration, fractional dilution of spirometric helium is proportional to lung volume. Equilibration is affected by leaks in the spirometer tubing, slight solubility of helium in tissue, inaccurately compensated change in volume of the combined lung-spirometer system associated with physiologic gas exchange, and helium meter drift. ${ }^{15}$ Because measurement error cannot be entirely eliminated, equilibration is defined as a threshold rate of change in helium concentration. Patients with severe COPD may have areas of lung where gas mixing is so slow that equilibration proceeds at a rate less than this threshold. The resulting underestimated volume is often referred to as trapped gas, a term that suggests a fixed state. It may be more useful to consider this volume in terms of dynamic gas trapping relative to equilibration time. Indeed, it has been suggested that underestimation of lung volume by He-derived TLC may be attenuated by reducing the end-of-test criterion for minimal change in helium concentration from $0.05 \%$ to $0.02 \%$ in $30 \mathrm{~s}$ of rebreathing, allowing more time for equilibration (often $>7 \mathrm{~min}$ ), and making frequent inspiratory capacity maneuvers during equilibration to open previously closed lung regions.,15 The demonstration by Rodenstein and Stănescu ${ }^{20}$ that He-derived

Table 3-Analysis of Variance for Within-Subject Variance of TLC by Test Type and Test Site, in Subjects With Airflow Obstruction

\begin{tabular}{|c|c|c|c|}
\hline Outcome & Variance Source & $F$ Ratio & $P$ Value \\
\hline \multirow[t]{4}{*}{ Within-subject TLC } & Test type & 6.48 & .002 \\
\hline & Site & 0.57 & .565 \\
\hline & Interaction & & \\
\hline & Test $\times$ site & 1.68 & .156 \\
\hline \multicolumn{4}{|c|}{ Post hoc Comparison (Scheffe) } \\
\hline Volume Comparison & Mean Difference (L) & $P$ Value & $95 \% \mathrm{CI}$ \\
\hline Pleth - He & 0.93 & $<.001$ & $0.36-1.50$ \\
\hline Pleth - CT scan & 1.08 & $<.001$ & $0.50-1.64$ \\
\hline $\mathrm{He}-\mathrm{CT}$ scan & 0.15 & .820 & -0.42 to 0.71 \\
\hline
\end{tabular}

See Table 2 for expansion of abbreviations. 
Table 4-Logistic Regression of $>1$ L TLC Difference by Technique as a Function of Severely Reduced FEV $(<30 \%$ Predicted) Among Subjects Without Restrictive Defect (TLC > 79\%)

\begin{tabular}{|c|c|c|c|c|}
\hline $\begin{array}{l}\text { Dependent Volume } \\
\text { Difference }(>1 \mathrm{~L} \text { vs } \leq 1 \mathrm{~L})\end{array}$ & $\begin{array}{c}\text { Independent } \\
\operatorname{FEV}_{1}(\geq 30 \% \text { vs }<30 \%)\end{array}$ & $P$ Value & OR & $95 \%$ CI \\
\hline Pleth - CT scan & $\ldots$ & .035 & 2.45 & $1.06-5.63$ \\
\hline Pleth - He & $\ldots$ & .031 & 2.53 & $1.09-5.86$ \\
\hline $\mathrm{He}-\mathrm{CT}$ scan & $\ldots$ & .151 & 0.24 & $0.10-1.43$ \\
\hline
\end{tabular}

$\mathrm{OR}=$ odds ratio. See Table 2 for expansion of other abbreviations.

TLC underestimates trapped gas volume in airflow obstruction may have been biased by use of 7-min closed-circuit He technique without adherence to present end-of-test standards for equilibration. ${ }^{20} \mathrm{We}$ found that $50 \%$ of our subjects with severe airflow obstruction required $>7$ min for helium equilibration. If we limited He-derived TLC to 7-min rebreathing time, we too would have systematically underestimated TLC. These newer strategies should reduce volume underestimation due to dynamic gas trapping.

Measurement of thoracic gas volume (TGV) by whole-body Pleth was described by DuBois et al. ${ }^{21}$ Subjects make ventilatory efforts against a shuttered mouthpiece while sitting in a closed container (body box). The ratio of pressure change within the lung (measured at the airway opening) to pressure change within the body box is proportional to the ratio of lung volume to box volume. This method can accurately estimate the volume of thoracic gas undergoing pressure change similar in phase and amplitude to that at the airway opening, irrespective of communication with the airway during breathing.

There are several potential sources of measurement error that may limit plethysmographic accuracy in the setting of obstructive disease. These include frequencyof-panting-dependent overestimation of TGV associated with incomplete equilibration of mouth and alveolar pressures, heterogeneity of alveolar pressure swings during the panting maneuver, and excessive compliance of the extrathoracic airway. ${ }^{5,10}$ Shore and colleagues $^{10}$ demonstrated that plethysmographic overestimation of lung volume in COPD is significantly attenuated by a combination of low panting frequency $(\leq 1 \mathrm{~Hz})$ and cheek support to minimize compliance of the extrathoracic airway. Although their data suggest adequate equilibration of mouth and alveolar pressure during slow panting among subjects with airflow obstruction, their sample did not include subjects with very severe obstruction. It may be that end-tidal equilibration of mouth and alveolar pressure is not adequate in severe airflow obstruction even during panting frequency of 0.5 to $1 \mathrm{~Hz}$.

After its introduction in 1956, studies using plethysmographic measurement of thoracic gas volume suggested that $\mathrm{He}$ and gas washout techniques sys- tematically underestimate lung volume in patients with airflow obstruction. ${ }^{22-24}$ Prior to that time, various studies of lung volume using techniques that relied on gas distribution or washout provided equivocal results with regard to the question of increased TLC in obstructive lung disease. ${ }^{25,26}$ With the assumption that Pleth was accurate, results obtained using this technique indicated that TLC tends to be elevated in airflow obstruction, especially when there is emphysema. Medical texts began to reflect the conclusion that TLC was increased in various obstructive pathologies. As stated in the second edition of the classic Respiratory Function in Disease: "Since an increase in total lung capacity commonly occurs in emphysema, increase in lung size may be a major criterion of emphysema...."27 It was not until 1978 that Brown and Slutsky ${ }^{6}$ demonstrated frequency-dependent discrepancies in the measurement of thoracic gas volume among patients with asthma, a result suggesting that reported increases in TLC in asthma may have been largely an artifact of Pleth. By that time Pleth had become a standard technique in clinical medicine and research. In the clinical laboratory, Pleth requires substantially less time to perform than does gas dilution, particularly in the assessment of patients with airflow obstruction. Coupled with its presumed superior accuracy there seemed to be good reasons to favor the body box over He or nitrogen washout. Although evidence accrued regarding frequencydependent overestimation of TGV among patients with airflow obstruction, the studies of Rodenstein and Stănescu, and Shore et al, provided guidance for proper plethysmographic technique to avoid this spurious overestimation of lung volume $\mathrm{e}^{9,10}$ in moderate obstruction. However, confidence in the accuracy of this technique in severe obstruction may have been unwarranted.

We believe there is compelling reason to establish the relative accuracy of Pleth- and He-derived measurements of TLC in the setting of severe airflow obstruction. COPD is the fourth leading cause of mortality in the United States, accounting for more than 100,000 deaths per year and marked disability during the final years of life. ${ }^{28}$ Given high rates of morbidity and mortality, there has been considerable recent interest in identifying factors associated with 
both COPD survival and the efficacy of treatments such as LVRS to improve functional status in endstage disease. Results from The National Emphysema Treatment Trial and other investigations suggest that both COPD mortality and functional improvements associated with LVRS depend on physiologic characteristics, such as hyperinflation. 11,29-32 Furthermore, patients with very severe COPD are at unacceptably high risk of perioperative death following LVRS. ${ }^{33}$ To the extent that gas trapping and hyperinflation are potentially treatable factors contributing to dysfunction in COPD, accurate measurement of lung volume may be particularly important for selection of candidates most likely to benefit from lung volume reduction.

In summary, we used three techniques to measure total lung capacity in a large sample of patients, many of whom had severe airflow obstruction. We tested the hypothesis that, within the limits of measurement accuracy across techniques, Pleth would overestimate TLC relative to the other two techniques in subjects with severe airflow obstruction. We were able to reject the null hypothesis, and furthermore demonstrated a dose-dependent effect in plethysmographic overestimation of TLC that is consistent with results of previous physiologic research. Our findings support the hypothesis that, in severe airflow obstruction, Pleth may systematically overestimate TLC even when performed at a panting frequency of 0.5 to $1 \mathrm{~Hz}$.

Are there further modifications of plethysmographic technique that can improve accuracy in the setting of severe airflow obstruction? The data of Brown and Slutsky ${ }^{6}$ suggested that during the panting maneuver in COPD, interregional pressure differences may occur that would cause mouth pressure swings not to equal alveolar pressure swings. In that study, He-derived TLC and Pleth-derived TLC were virtually identical when alveolar pressure swings were slow and measured by esophageal balloon with the panting maneuver performed near TLC, which should reduce the time required for pressure equilibration along the airways. These uncertainties need to be assessed independently in ongoing attempts to clarify whether Pleth should still be considered the preferred technique for measuring lung volume in the setting of obstructive disease.

\section{ACKNOWLEDGMENTS}

Author contributions: Dr O'Donnell: contributed to study design, subject enrollment, measurements, data management and analysis, and manuscript preparation.

Dr Bankier: contributed to study design and manuscript preparation.

Dr Stiebellehner: contributed to subject recruitment, measurements, and manuscript preparation.

Dr Reilly: contributed to study design and manuscript preparation. Dr Brown: contributed to study design and manuscript preparation.
Dr Loring: contributed to study design, measurement, analysis, and manuscript preparation.

Financial/nonfinancial disclosures: The authors have reported to CHEST that no potential conflicts of interest exist with any companies/organizations whose products or services may be discussed in this article.

Other contributions: We thank Mr Richard Johnston and Ms Diane Saunders, Chief Pulmonary Function Technicians at, respectively, Beth Israel Deaconess Medical Center and Brigham and Women's Hospitals, Boston, MA, for their excellent work. We also thank Dr Arthur Dubois for his interest and constructive criticism regarding interpretation of our results. This work was performed at: The Beth Israel Deaconess Medical Center, Boston The Brigham and Women's Hospital, Boston; and The Medical University of Vienna Hospital, Vienna.

\section{REFERENCES}

1. Schaanning CG, Gulsvik A. Accuracy and precision of helium dilution technique and body plethysmography in measuring lung volumes. Scand J Clin Lab Invest. 1973;32(3):271-277.

2. Quanjer PH, Tammeling GJ, Cotes JE, Pedersen OF, Peslin R, Yernault JC; Official Statement of the European Respiratory Society. Lung volumes and forced ventilatory flows. Report Working Party Standardization of Lung Function Tests, European Community for Steel and Coal. Official statement of the European Respiratory Society. Eur Respir J Suppl. 1993; 16:5-40.

3. Wanger J, Clausen JL, Coates A, et al. Standardisation of the measurement of lung volumes. Eur Respir J. 2005;26(3): 511-522.

4. Stănescu DC, Rodenstein DO. Which method for measuring lung volume in airway obstruction [abstract]. Presented at American Thoracic Society Annual Meeting; May, 1982.

5. Rodenstein DO, Francis C, Stănescu DC. Airway closure in humans does not result in overestimation of plethysmographic lung volume. J Appl Physiol. 1983;55(6):1784-1789.

6. Brown R, Slutsky AS. Frequency dependence of plethysmographic measurement of thoracic gas volume. J Appl Physiol. 1984;57(6):1865-1871.

7. Brown R, Ingram RH Jr, McFadden ER Jr. Problems in the plethysmographic assessment of changes in total lung capacity in asthma. Am Rev Respir Dis. 1978;118(4):685-692.

8. Rodenstein DO, Stănescu DC, Francis C. Demonstration of failure of body plethysmography in airway obstruction. J Appl Physiol. 1982;52(4):949-954.

9. Rodenstein DO, Stănescu DC. Frequency dependence of plethysmographic volume in healthy and asthmatic subjects. J Appl Physiol. 1983;54(1):159-165.

10. Shore SA, Huk O, Mannix S, Martin JG. Effect of panting frequency on the plethysmographic determination of thoracic gas volume in chronic obstructive pulmonary disease. Am Rev Respir Dis. 1983;128(1):54-59.

11. Andersson LG, Ringqvist I, Walker A. Total lung capacity measured by body plethysmography and by the helium dilution method. A comparative study in different patient groups. Clin Physiol. 1988;8(2):113-119.

12. Fishman A, MartinezF, Naunheim K, etal; National Emphysema Treatment Trial Research Group. A randomized trial comparing lung-volume-reduction surgery with medical therapy for severe emphysema. N Engl J Med. 2003;348(21):2059-2073.

13. Bankier AA, O'Donnell CR, Bosielle PM. Respiratory instructions for CT examinations of the lungs: a hands-on guide. Radiographics. 2008;28(4):919-931.

14. Denison DM, Morgan MD, Millar AB. Estimation of regional gas and tissue volumes of the lung in supine man using computed tomography. Thorax. 1986;41(8):620-628. 
15. Brown R, Leith DE, Enright PL. Multiple breath helium dilution measurement of lung volumes in adults. Eur Respir J. 1998;11(1):246-255.

16. Bland JM, Altman DG. Statistical methods for assessing agreement between two methods of clinical measurement. Lancet. 1986;1(8476):307-310.

17. Stoel BC, Putter H, Bakker ME, et al. Volume correction in computed tomography densitometry for follow-up studies in pulmonary emphysema Proc Am Thorac Soc. 2008;5(9):919-924.

18. WeinstockTG, Roberts DH, Loring SH, O’Donnell CR. Postural Dependence of Vital Capacity in Assessment of Diaphragm Dysfunction. Poster presented at American Thoracic Society Annual Meeting; May 17-20, 2009; San Diego, CA.

19. Meneely GR, Kaltreider NL. The volume of the lung determined by helium dilution. Description of the method and comparison with other procedures. J Clin Invest. 1949; 28(1):129-139.

20. Rodenstein DO, Stănescu DC. Reassessment of lung volume measurement by helium dilution and by body plethysmography in chronic air-flow obstruction. Am Rev Respir Dis. 1982;126(6):1040-1044.

21. Dubois AB, Botelho SY, Bedell GN, Marshall R, Comroe JH Jr. A rapid plethysmographic method for measuring thoracic gas volume: a comparison with a nitrogen washout method for measuring functional residual capacity in normal subjects. J Clin Invest. 1956;35(3):322-326.

22. Renzetti AD Jr, Eastman G, Auchincloss JH Jr, Gilbert R, Eich R, Dutton R. Physiologic defects in chronic bronchitis. Am Rev Tuberc. 1958;78(2):191-202.

23. Bedell GN, Marshall R, Dubois AB, Comroe JH. Plethysmographic determination of the volume of gas trapped in the lungs. J Clin Invest. 1956;35(6):664-670.

24. Ross JC, Copher DE, Teays JD, Lord TJ. Functional residual capacity in patients with pulmonary emphysema. A comparative study using gas dilution and plethysmographic techniques for measurement. Ann Intern Med. 1962;57:18-28.

25. Hurtado A, Kaltreider NL, Fray WW, Brooks WD, McCann WS. Studies of total pulmonary capacity and its sub-divisions. VI. Observations on cases of obstructive pulmonary emphysema. J Clin Invest. 1934;13(6):1027-1051.

26. Baldwin ED, Cournand A, Richards DW Jr. Pulmonary insufficiency; a study of 122 cases of chronic pulmonary emphysema. Medicine (Baltimore). 1949;28(2):201-237.

27. Bates DV, Macklem PT, Christie RV. Respiratory Function in Disease. Philadelphia, PA: W.B. Saunders Co.; 1971:165.

28. Mannino DM, Homa DM, Akinbami LJ, Ford ES, Redd SC. Chronic obstructive pulmonary disease surveillance-United States, 1971-2000. MMWR Surveill Summ. 2002;51(6): $1-16$.

29. Casanova C, Cote C, de Torres JP, et al. Inspiratory-to-total lung capacity ratio predicts mortality in patients with chronic obstructive pulmonary disease. Am J Respir Crit Care Med. 2005;171(6):591-597.

30. Ingenito EP, Loring SH, Moy ML, Mentzer SJ, Swanson SJ, Reilly JJ. Physiological characterization of variability in response to lung volume reduction surgery. J Appl Physiol. 2003;94(1):20-30.

31. Fessler HE, Scharf SM, Permutt S. Improvement in spirometry following lung volume reduction surgery: application of a physiologic model. Am J Respir Crit Care Med. 2002;165(1):34-40.

32. Martinez FJ, Foster G, Curtis JL, et al; NETT Research Group. Predictors of mortality in patients with emphysema and severe airflow obstruction. Am J Respir Crit Care Med. 2006;173(12):1326-1334.

33. National Emphysema Treatment Trial Research Group. Patients at high risk of death after lung-volume-reduction surgery. N Engl J Med. 2001;345(15):1075-1083. 